\title{
ANALYSIS OF LIQUID VISCOSITY VALUE USING FALLING BALL METHOD USING DIGITAL IMAGE TECHNOLOGY BASED ON LONG EXPOSURE FEATURES
}

\author{
Noke Kesaulya*, Abdul Haji Amahoru, and Maria A. Hertiavi \\ Faculty of Education and Teacher Training, Pattimura University, Ambon \\ Jl. Ir. M. Putuhena, Poka-Ambon Indonesia, 40132 \\ *email: noke.kesaulya1977@gmail.com
}

\begin{abstract}
Physics is the science that studies natural phenomena which observation is one of the most important aspect. Observations were made to study the physical phenomena and, if necessary, measurements can be made using appropriate, easily accessible as well as sophisticated devices. In this study, observation and measurement of a straight motion in a viscometer tube device has been developed. The device is also able to measure viscosity of the liquid (indirectly) using the falling ball method by means of Long Exposure technique. The viscosity of a liquid is essentialy related to drag force that caused by friction between the liquid molecules, which are able to resist fluid flow. Long Exposure is a technique of image acquisition which can preserve information about traces of objects moving at a certain time that might not be able to be captured with the naked eye. The falling ball method is based on a measurement of terminal velocity of the falling ball in a viscous liquid. In the experiments, lightmeter is a solid ball with varying sizes coated with phosphorus paint which was released from the surface of the liquid (glycerin and honey) inside a cylindrical tube. A camera with long exposure feature is placed in front of a perforated disk that serves as a chopper, which are essentially slits for the camera to capture the trajectory of the ball and convert the continuous trace into discrete traces. Using a simple digital image processing and digital image analysis techniques, the traces of the trajectory of the ball can be analyzed and thus we can obtain the data of the position for each time interval, thus the speed of the ball can be observed and the type of the motion can be analyzed (accelerated and motion with constant velocity). The calculated liquid viscosity is 0.7885 Pa.s viscosity with error $6.55 \%$ for glycerin, and as for honey the viscosity is $3.9162 \mathrm{~Pa}$.s with precision of $99.98 \%$. It can be concluded that these devices can be used to observe the phenomenon of straight motion with constant velocity and accelerated motion in viscosity tube, determines the value of the viscosity of a liquid with a good accuracy and precision.
\end{abstract}

Keywords: viscosity, falling ball method, long exposure, straight motion.

\section{Introduction}

Physics is the branch of science concerned with the structure of matter and the interactions between the fundamental constituents of the observable universe. In studying the phenomena or natural phenomena, it is necessary to do a series of scientific processes starting from observation, measurement, analysis until drawing conclusions (Noval, 2015). To be able to make observations and measurements properly, we need tools that can work with measurement methods that are suitable and easily accessible as well as sophisticated. Some measurement devices have been able to present various variables in one measurement. For example in determining the viscosity value of a fluid, there are several measurement methods that can be used to obtain the expected results.

Fluid viscosity can be determined by various methods, including falling ball, rolling ball, capillary tube, concentric cylinder rotation (Couette), cone rotation of plates, parallel plates and Ford Cup (Walters and Jones, 1996). One of the most widely used methods is a falling ball, because the measurement technique is relatively easy to do. By knowing the 
force of thickness (drag force) of the fluid used, the value of viscosity can be determined. In this method, the viscosity force is analyzed using Stokes' Law, where the quantities that affect it are the radius of the ball $r$, and the velocity of ball $v$ relative to the fluid (Sears and Zemansky, 1982).

In the falling ball method, the important part is measuring the fall time of the ball dropped on the fluid. The main difference in various developments for this falling ball method is how to measure the speed of a falling ball (Warsito et al, 2012). Budianto (2008) uses linear regression to determine the viscosity of liquid based on the data obtained. A simulation of the measurement of viscosity of the lubricating oil has also been carried out using a microcontroller AT89S51 by Mujiman (2008). In addition there are also those who use coil sensors as a timer detector which is then processed to obtain the value of viscosity (Suciati and Sartono, 2009). In further development, it has also been done by using a video camera method to record the falling ball process then the image is processed and obtained the speed of fall (Brizard et al, 2005), and also using an optocoupler sensor that was acquired with a serial communication system to get the speed of the ball, then processed to get the value of viscosity (Warsito et al, 2012).

In measuring the speed of motion of a falling metal ball on a liquid in a tube, the interaction between the ball and the tube is very influential on the accuracy of the measurement results. The greater the diameter of the metal ball dropped into the tube containing water will tend to be forced to move away from the tube wall. This event is called the wall effect (Viswanath, 2007). The correction factor is then used by Brizard, Chusni, and Warsito in determining the value of fluid viscosity using the falling ball method.

Fluid viscosity measurement of falling ball method which has been done by viscosimeter to find the speed of the ball. The use of two boundaries for the distance of the ball falling in the fluid has not been based on clear information whether the ball has moved uniform speed or uniform acceleration. This causes uncertainty in the results of measurements of the viscosity of the liquid. While measurements made by Brizard et al using a video, can show the path of the ball during is moved, but a visualization of the ball position every time during the move in the fluid is not displayed in detail. So we have not been able to determine directly the area where the ball has uniform speed and uniform acceleration.

Based on this description, in this study developed a device for observing and measuring the viscosity of a liquid falling ball method using the Long Exposure technique. This technique utilizes a special way of recording images of a moving object, so that we can see the footprint and position of the ball when moving in liquid directly and can determine exactly where the two boundaries of the viscometer tube should be installed. From this image, position and time data can be obtained and then analyzed further.

\section{Research Methods}

In this study, the device made consists of several main parts that are used to acquire images. The device is composed of 1 simple electric motor chain, consisting of 3 batteries 1,5 volts, 1 battery holder, 1 switch, 1 dynamo, 1 pipe clamp arranged on a Printed Circuit Board (PCB). 1 ligthmeter as an object made with an iron ball coated with green phosphor paint which will radiate its own light in the dark. 1 cylindrical tube with a diameter of 56.5 $\mathrm{mm}$, height $40.3 \mathrm{~cm}$, and 1 android phone that has been equipped with a long exposure camera feature 2 . This device is placed on a holder that has been equipped with a camera 
buffer made using clamps $\mathrm{C}$. The size of the seat is made larger than that of a simple electric motor circuit with the aim of being able to eliminate the vibrations caused by the dynamo while rotating.

To produce discrete traces of lightmeter, the chopper is made of black acrylic material cut in a circle with a diameter of $\pm 28 \mathrm{~cm}$ and given 12 holes with a hole diameter of \pm 1.5 $\mathrm{cm}$. the distance between holes is made equal to $30^{\circ}$. The chopper is mounted on the dynamo at the center of the circle so that the rotation is stable. The shape of the device is made as in Figure 1.

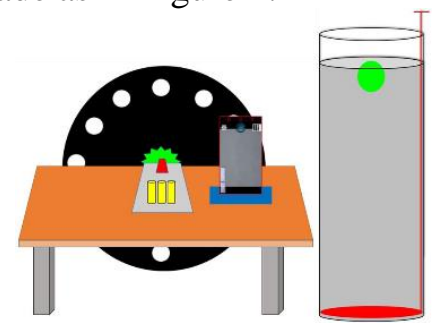

Figure 1. Illustration of a device with a Long Exposure technique

After the recording device and object are ready, complete the following steps:

a. Prepare tools and materials needed to conduct experiments.

b. The perforated Chopper is mounted on a dynamo series that has been given a holder.

c. Cell phones (Android) that have been equipped with the Long Exposure Camera 2 application are placed on the camera stand.

d. Position the camera on the phone so that it is right in the middle of one of the holes on the chopper

e. Rotate the chopper by turning on the dynamo, and make sure that the camera is in the center of the hole when the chopper rotates.

f. Wait \pm 5 minutes for the chopper rotation to stabilize

g. While waiting, on the phosphor ball so that the light is actually absorbed by the ball.

h. Put the phosphorus ball at the starting point on the surface of the liquid

i. Release the phosphor ball, while doing the recording by pressing the capture button on the camera.

j. Record the chopper spin as the phosphor ball moves using the Highspeed Camera. This recording is related to the time calibration to be performed.

k. Repeat steps (7) to (9) for variations in the size of the different balls (use balls 1,2,3).

1. Perform a calibration to change the track position of the phosphor ball in pixels to the unit length of the meter (meter).

$\mathrm{m}$. The position of the phosphor ball is detected by recording the pixel position of each point of light using the Matlab software. Position calibration process as in Figure III.9

n. With the results of the recording done in step 10, the time of the phosphorus ball is determined by calculating the time interval between one point and another by calculating the chopper rotation period by counting the number of frames when the chopper moves one full turn then divided by the framerate from the camera then divided by the number of holes in the chopper. 

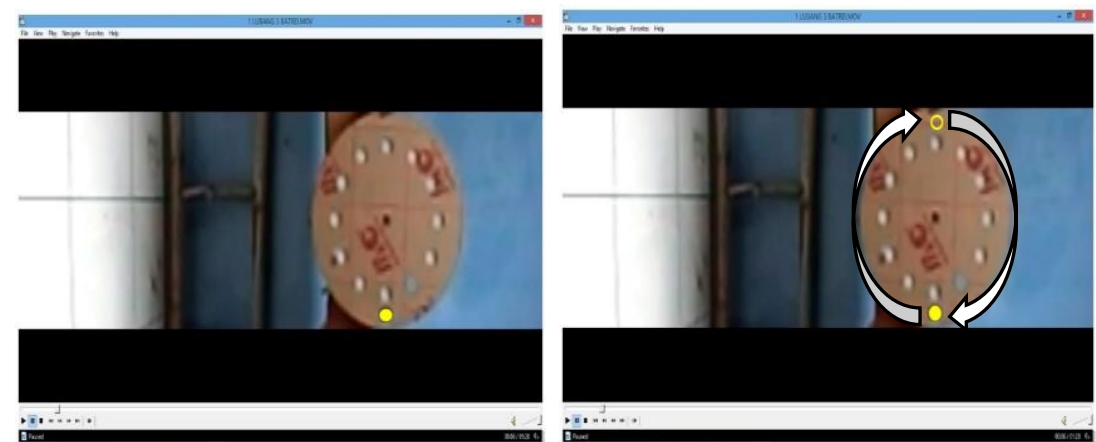

Figure 2. Position and Time Calibration

o. Using MS Excel software, make a table observing the position of time and then plot it into a graph.

p. Linear data on the graph shows that the phosphor sphere is moving in a straight line or in other words has reached its maximum speed. With linear regression, a linear equation $y=m x$ will be obtained, where the slope value of $m$ is the velocity value of the phosphor ball.

\section{Results And Discussion}

a. Results

After a series of data collection processes, an image of a moving phosphorus ball is obtained as shown in Figure 3 and Figure 4 below.

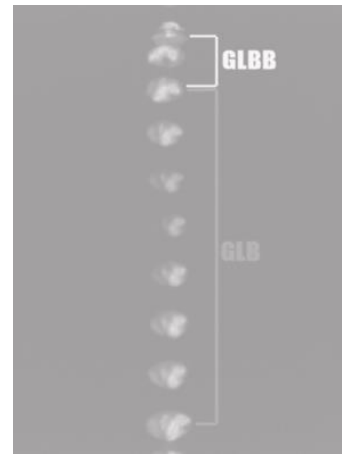

(a)

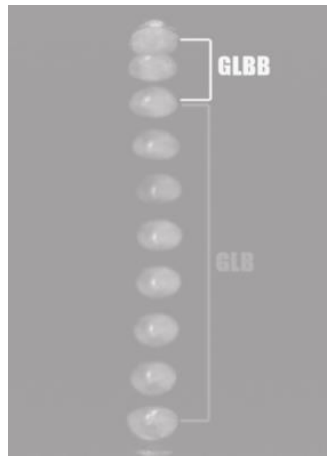

(b)

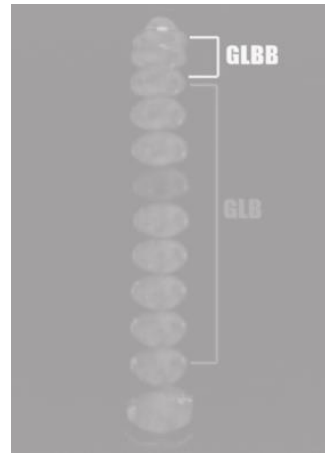

(c)

Figure 3. Traces of phosphorus spheres in the form of dots of light (discrete) on glycerin; (a) ball 1 (b) ball 2 (c) ball 3 


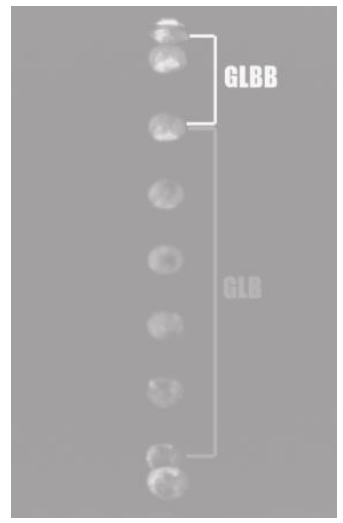

(d)

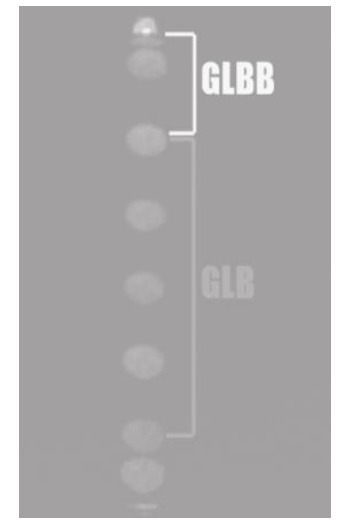

(e)

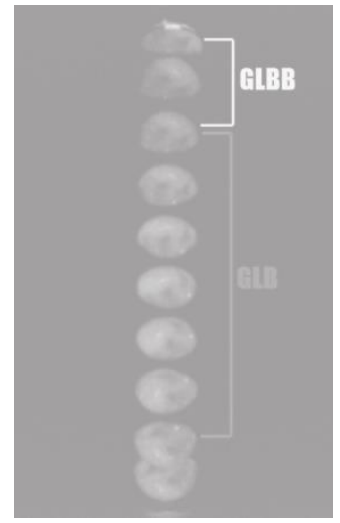

(f)

Figure 4. Traces of phosphorus balls in the form of dots of light (discrete) in honey; (d) ball 1 (e) ball 2 (f) ball 3

Using the help of Matlab software, then by calculating the chopper rotation period as shown in Appendix $\mathrm{H}$, position and time interval data for each variation in the number of chopped chopper can be obtained. After these data are plotted into a position and time relationship graph, the results for each number of counts are obtained as shown in Figure 8-13.

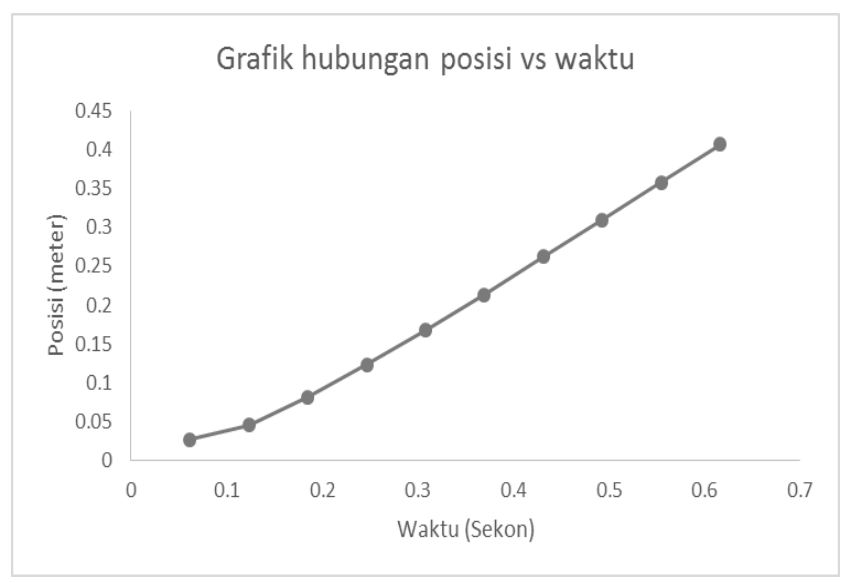

Figure 5. Graph of position versus time for ball 1 in glycerin

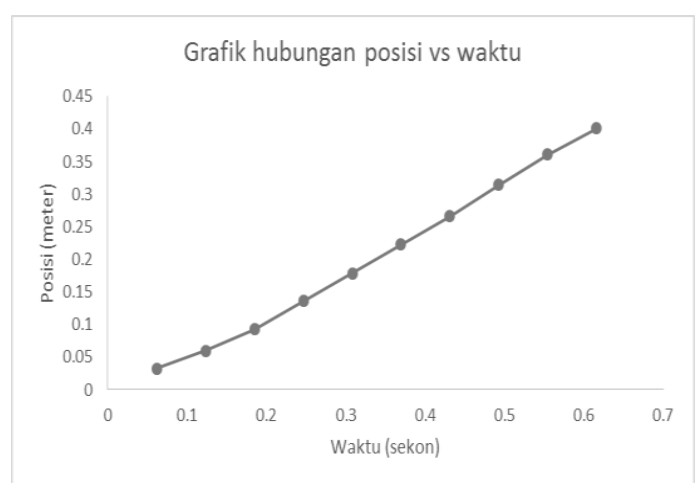

Figure 6. Graph of position versus time for ball 2 on glycerin 


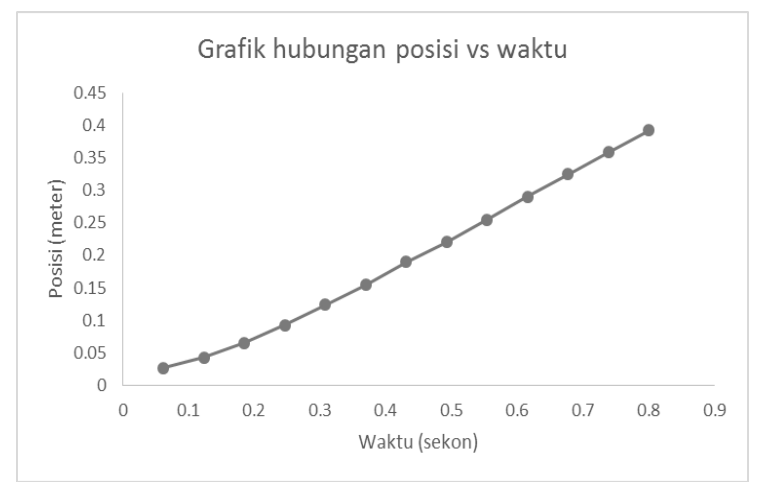

Figure 7. Graph of position versus time for ball 3 on glycerin

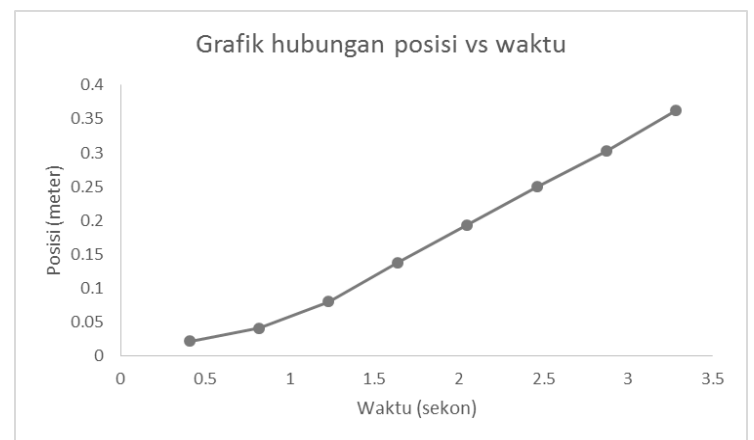

Figure 8. Graph of position versus time for ball 1 in honey

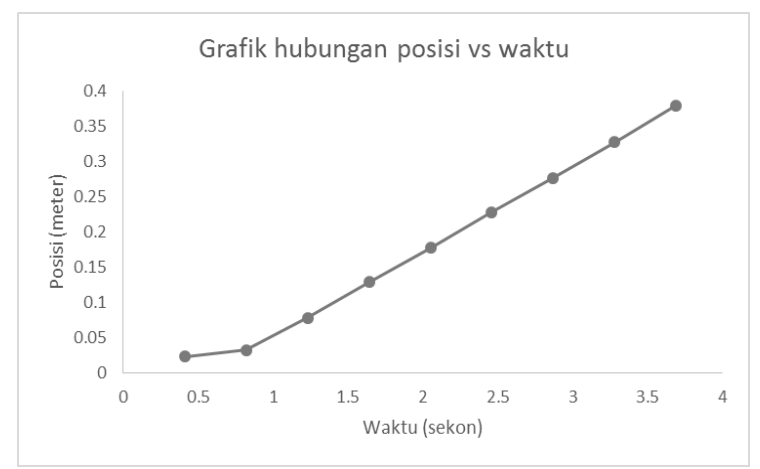

Figure 9. Graph of position versus time for ball 2 in honey 


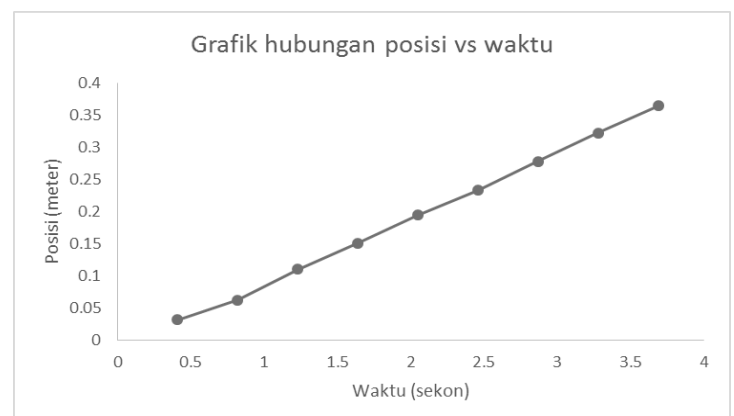

Figure 10. Graph of position versus time for ball 3 in honey

Based on the position and time interval of the graph in Figure 8-13, we can then determine the value of the terminal velocity which will then be used to determine the viscosity value of the liquid being passed by the ball. The linear region on the graph shows that the ball is moving at a constant speed. Therefore, to obtain the value of the terminal speed, it is enough to analyze the linear part as in Figure 14-15.

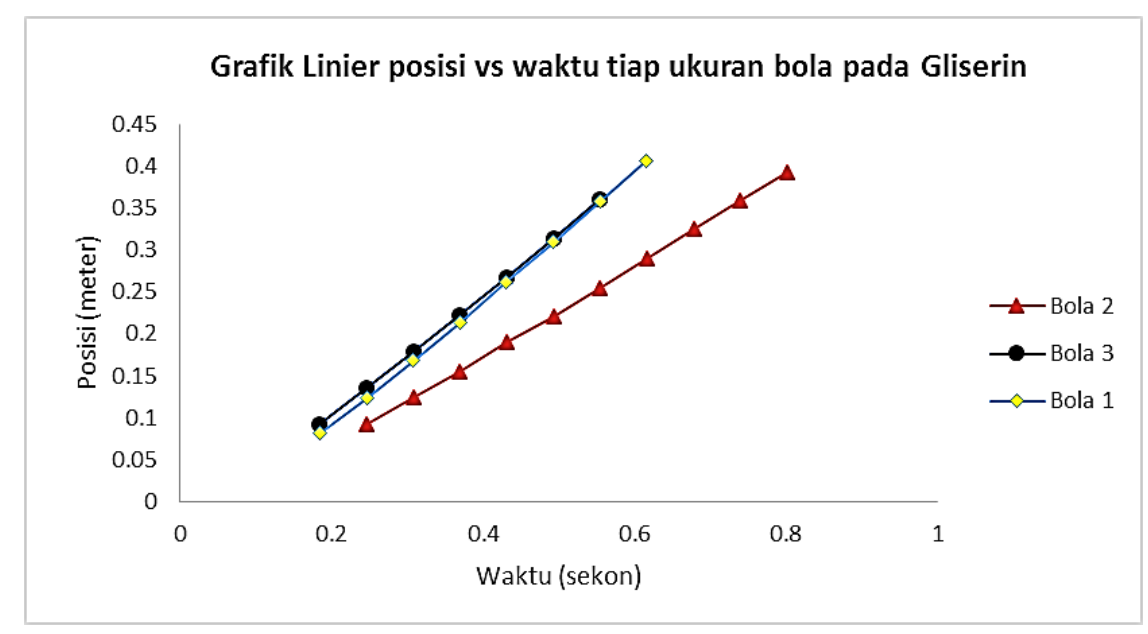

Figure 11. Linear graph of position with respect to time for each ball in Glycerin

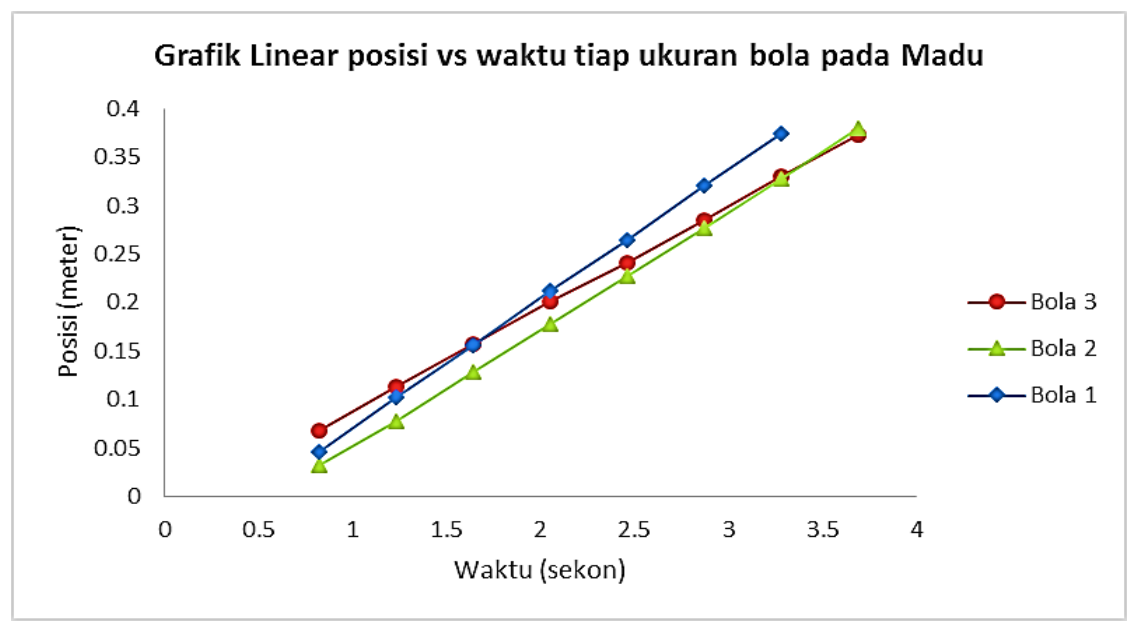

Figure 12. Linear graph of position versus time for each ball in Honey 


\section{b. Discussion}

The image captured by the camera can be seen in Figures 6 and 7. Overall, it can be seen that the trace of the phosphor ball is in the form of dots of light (discrete), which arises, which shows the position of the phosphor ball at each time interval and has a pattern of motion. At first the phosphor ball moves accelerated with ever-increasing speed due to the influence of the acceleration of Earth's gravity, or it can be said that the phosphor ball moves straight to uniform acceleration (GLBB).

A moment ago, after cover a certain distance, the gravity of the ball will be as great as the buoyancy, plus the frictional force of the liquid. As a result the phosphor ball moves at a constant speed or it can be said that the phosphor ball has been uniform speed (GLB). This fixed speed is called the final speed or terminal speed. This can be observed from the image display ie the distance between one point to another tends to be the same. This can be observed from the image display that is the distance between points tends to be the same.

In addition to image capture, to determine uniform speed (GLB) and uniform acceleration (GLBB) more accurately, further analysis can be done to find out the position and time interval of the moving phosphor ball from being released until it stops.

From the view of the image, it can be seen the area where the ball is still experiencing uniform acceleration (GLBB) in the glycerin liquid is $\pm 5.47 \mathrm{~cm}$ for ball $1, \pm 6.01 \mathrm{~cm}$ for ball 2 , and $\pm 6.55 \mathrm{~cm}$ for ball 3 from the initial point released. Whereas in honey liquid, the ball still experiences GLBB as far as $\pm 5,88 \mathrm{~cm}$ for ball $1, \pm 6.81 \mathrm{~cm}$ for ball 2 , and \pm 8.37 $\mathrm{cm}$ for ball 3 from the initial point of release. After that, due to the balance of forces which works on the ball during the move, the ball will be having uniform speed (GLB) until the ball stops.

By using linear regression from each graph, the terminal speed values are obtained as shown in and Table 1.

Table 1. Average terminal speeds for each ball size

\begin{tabular}{|c|c|c|c|c|c|}
\hline \multirow{2}{*}{ No } & \multirow{2}{*}{$\begin{array}{c}\text { Ball } \\
\text { size }\end{array}$} & \multicolumn{2}{|c|}{$v(\mathrm{~m} / \mathrm{s})$} & \multicolumn{2}{c|}{ Precision (\%) } \\
\cline { 3 - 6 } & Glycerin & Honey & Glycerin & Honey \\
\hline 1 & Ball 1 & 0.758 & 0.133 & 99.59 & 99.98 \\
\hline 2 & Ball 2 & 0.724 & 0.121 & 96.95 & 99.98 \\
\hline 3 & Ball 3 & 0.543 & 0.106 & 97.30 & 99.95 \\
\hline
\end{tabular}

The viscosity value of a liquid can be determined after the terminal velocity of the ball is known by entering a correction factor between the diameter of the ball $\mathrm{d}$ and the diameter of the tube wall $\mathrm{D}$. This correction becomes important because when a metal ball is dropped into a tube containing water, the ball will tend to be forced to move away from the tube wall, which resulted in turmoil from turbulence edge flow. The movement of the ball will screw up the fluid, and finally the ball's movement becomes irregular. The viscosity values of the liquid used are shown in Table 2. 
Table 2. Glycine viscosity values for each ball size

\begin{tabular}{|c|c|c|c|c|c|}
\hline No & Ball size & Ratio d/D & $\eta_{\exp }$ (Pa.s) & $\begin{array}{l}\eta_{\text {measured }} \\
\text { (Pa.s) }\end{array}$ & Error (\%) \\
\hline 1 & Ball 1 & 0.490813 & 3.2976 & 0.6179 & 26.76 \\
\hline 2 & Ball 2 & 0.549823 & 4.3781 & 0.6253 & 25.89 \\
\hline 3 & Ball 3 & 0.668198 & 8.6552 & 0.7885 & 6.55 \\
\hline
\end{tabular}

Table 3 Value of honey viscosity for each ball size

\begin{tabular}{|c|c|c|c|c|}
\hline No & Ball size & Ratio d/D & $\eta_{\exp }$ (Pa.s) & $\eta_{\text {measured }}$ (Pa.s) \\
\hline 1 & Bola 1 & 0.490813 & 18.2719 & 3.4238 \\
\hline 2 & Bola 2 & 0.549823 & 25.4517 & 3.6351 \\
\hline 3 & Bola 3 & 0.668198 & 42.9878 & 3.9162 \\
\hline
\end{tabular}

The data in Table 1. shows that the greater the ball's size, the greater the time it takes for the ball to move in fluid, or in other words, the speed of the ball decreases. It can also be seen that for the speed of the ball in honey is smaller than glycerin, this corresponds to the viscosity level of the two liquids. From the data in Table 2 and Table 3 it can be seen that the larger ball size also results in better viscosity values. For glycerin, the best value obtained is close to the reference viscosity value of $0.8438 \mathrm{~Pa} . \mathrm{s} \mathrm{d}$. An error value of $6.55 \%$ indicates a good level of accuracy. For honey, the error value cannot be calculated because the refference value of honey viscosity is very diverse. But with reference to accuracy in glycerin, it can be said that the honey viscosity value obtained has a good level of precision. Overall, these results indicate that the smaller the ratio between the diameter of the sphere and the diameter of the tube, the better the viscosity value obtained.

\section{Conclusion}

The experimental results show that the long exposure technique can display discrete traces, so thatthe position and time of the moving phosphorus in the viscometer tube can be obtained. With the ratio between the diameter of the ball and the diameter of the tube is 0.668 , the best viscosity value obtained is close to the reference viscosity value, which is 0.7885 Pa.s with an error of $6.55 \%$ for glycerin and the best viscosity value for honey is 3.9162 Pa.s. Thus it can be concluded:

a. Uniform speed (GLB) and uniform acceleration (GLBB) on tube viscosity falling ball method (falling ball) can be observed carefully using the long exposure technique.

b. The viscosity value of a liquid can be measured with a good degree of accuracy and very good precision using the long exposure technique.

\section{REFERENCES}

A. Budianto, Metode Penentuan Koefisian Kekentalan Zat Cair Dengan Menggunakan Regresi Linear Hukum Stokes. SEMINAR NASIONAL IV SDM TEKNOLOGI NUKLIR, (2008)

C. Lobo, Long Exposure Autumn Waterfalls. November. Accessed Desember 13, 2015. http://www.forestwander.com/2010/11/long-exposure-autumn-waterfalls/ (2010)

D. C. Giancoli, Fisika. Jakarta, Erlangga (2001) 
Digifotografi, memahami-long-exposure-photography. Agustus 26. Accessed September 23, 2015. https://digifotografi.wordpress.com/2011/08/26/memahami-long-exposurephotography/ (2011)

D. S. Viswanath, Viscosity of Liquids: Theory, Experiment, and Data. Dordrecht, Springer (2007).

E. Preliana, Pengembangan Alat Peraga Sains Fisika Berbasis Lingkungan untuk Materi Listrik Statis pada Siswa Kelas IX SMP Negeri 3 Pleret, JURNAL RISET DAN KAJIAN PENDIDIKAN FISIKA UAD, Volume: 2 (2015)

I. Milano, Long Exposure with Steel Wool Lit On Fire. Januari 4. Accessed Desember 13, 2018.

http://orig03.deviantart.net/76b9/f/2013/014/d/0/long_exposure_with_steel_wool_lit _on_fire_by_igormilano-d5rhio6.jpg (2013)

K. Walter, W. Jones, Measurement of Viscosity. Dalam Instrument Technology: Mechanical Measurements. London, Butterworths (1985)

M. Brizard, M. Megharfi, C. Verdier, E. Mahe, Design of a High Precision Falling Ball Viscometer. AMERICAN INSTITUTE OF PHYSICS, Volume: 76 (2005).

R. A. Serway, J. W. Jewett, FISIKA untuk sains dan teknik. Jakarta, Salemba Teknika (2009).

Sears, Zemansky, Fisika Untuk Universitas 1 (Mekanika, Panas, Bunyi). Bandung, Binacipta (1982).

S. Higashi, Graffiti of Speed Symmetric Long Exposure Photography. Maret. Accessed Desember 13, 2018. http://gencept.com/wp-content/uploads/2013/03/Graffiti-ofSpeed-Symmetric-Long-Exposure-Photography-by-Shinichi-Higashi_01-@_ GenCept.jpg (2013).

S. W. Suciati, A. Sartono, Pemanfaatan Sensor Koil Sebagai Detektor Pencatat Waktu Pada Viscometer Metode Bola Jatuh Berbasis Komputer. SEMINAR HASIL PENELITIAN DAN PENGABDIAN KEPADA MASYARAKAT. Lampung: Universitas Lampung. (2009).

Warsito, S. W. Suciyati, D. Isworo, Desain dan Analisis Pengukuran Viskositas Dengan Metode Bola Jatuh Berbasis Sensor Optocoupler dan Sistem Akuisisnya Pada Komputer. JURNAL NATUR INDONESIA Vol: 3 (2012).

Y. Nakamura, Fotografi Long Exposure. Agustus 6, Accessed Nopember 11, 2018, http://www.canon-asia.com/snapshot/id/eos-tips-917/ (2015). 